九州大学学術情報リポジトリ

Kyushu University Institutional Repository

\title{
Molecular Analysis of ITS Region and Antibacterial Activities of Stereum hirsutum
}

\section{Imtiaj, Ahmed}

Laboratory of Forest Resources Management, Division of Forest Environment Sciences, Department of Agro-Environment Sciences, Faculty of Agriculture, Kyushu University

Lee, Tae Soo

Department of Biology, University of Incheon

Ohga, Shoj i

Laboratory of Forest Resources Management, Division of Forest Environment Sciences, Department of Agro-Environment Sciences, Faculty of Agriculture, Kyushu University

https://doi.org/10.5109/20309

出版情報 : 九州大学大学院農学研究院紀要. 56 (2)，pp. 199-204，2011-09. 九州大学大学院農学研究院 バージョン：

権利関係 : 


\title{
Molecular Analysis of ITS Region and Antibacterial Activities of Stereum hirsutum
}

\author{
Ahmed IMTIAJ, Tae Soo LEE ${ }^{1}$ and Shoji OHGA* \\ Laboratory of Forest Resources Management, Division of Forest Environment Sciences, \\ Department of Agro-Environment Sciences, Faculty of Agriculture, \\ Kyushu University, Sasaguri, Fukuoka 811-2415, Japan \\ (Received April 4, 2011 and accepted May 9, 2011)
}

\begin{abstract}
Stereum hirsutum is one of the multicolored medicinal mushrooms belongs to Stereaceae, Basidiomycota. Identification of this mushroom is often confused with Trametes versicolor, the so called "true" Turkey tail. Because of that we studied ITS (internal transcribe spacer) region and PCR analysis to confirm the species. According to the taxonomic report of BLAST, obtained result of sequence having 558 bp length and $179.45 \mathrm{kDa}$ weight indicates that the studied fungus was $S$. hirsutum which similar to NCBI database (maximum and total score 1048, query coverage 100\% and maximum identity $99 \%$ compare to consensus reference strain dd08031, No. gil226346602I FJ810148.1). BLAST also computes a pairwise alignment between the query and database sequences searched. In neighbor joining tree, sequence of studied sample was placed with consensus other similar sequences of database mentioning the taxonomic name and sequence title that also indicate the studied sample was supposed to be $S$. hirsutum species. The findings of optical density referred that the filtrates of $S$. hirsutum was found to inhibit both Gram positive and Gram negative bacteria. Bacillus subtilis and Pseudomonas aeruginosa are highly inhibited by the culture filtrates. The lowest inhibition was found for Klebsiella pneumoniae but after 24 hours of incubation inhibition rate was accelerated. The results obtained from the paper disc method, all of 5 bacteria were less or more inhibited by the 3 types of culture filtrates. Liquid culture and water extracts were demonstrated the lowest and highest inhibition zones of studied bacteria, respectively. In liquid culture, the highest and lowest inhibitions were found to be seen for Staphylococcus aureus and Escherichia coli, respectively. In case of water and ethanol extracts, $P$. aeruginosa, S. aureus and B. subtilis were highly inhibited, respectively as well as $E$. coli and $K$. pneumoniae were less inhibited in all extracts.
\end{abstract}

\section{INTRODUCTION}

Stereum hirsutum is one of the multicolored medicinal mushrooms belongs to Stereaceae, Basidiomycota. The fungus $S$. hirsutum is inedible, wavy, leathery shelves are a common sight in Bay area woodlands. Fresh fruiting body of the fungus is bright orange-brown to orange-buff, fading in age or dry weather to dull-buff or grey. As the common name suggests, S. hirsutum is often confused with Trametes versicolor, the so called "true" Turkey tail. That is why; many people may wrong to identify this fungus and even each of $S$. hirsutum and T. versicolor often be considered as other. In spite of this difficulty it could also be said that the genus Stereum has long been old background for folk remedies even without any information of which bio-compounds are in charge. The ethnobotanical uses of this fungus to heal both human and plant diseases have been accumulated but scientific evidences are not yet well recognized. Newly, some novel and potential compounds such as a sesquiterpene, three aromatic compounds and a known compound methyl 2, 4-dihydroxy-6-methylbenzoate were isolated from a culture broth of the fungus Stereum sp. The novel sesquiterpene was determined to be stereumone and the three new aromatic compounds were elucidated together with the known compound. The combination of these compounds showed evident nemati-

${ }^{1}$ Department of Biology, University of Incheon, Incheon 402749 , Korea

* Corresponding author (E-mail: ohga@forest.kyushu-u.ac.jp) cidal activity against nematode Panagrellus redivivus (Li et al., 2006).

Because of that, to avoid the confusion of wrong identification a molecular technique was performed. Beside this, to find out the effective antimicrobial compounds we studied liquid cultures filtrate, water and ethanol extract of solid culture of this fungus extensively, expecting that the cultures contain the similar compounds as the basidiocarp. Here, we reported information about molecular identification and antibacterial activities of $S$. hirsutum.

\section{MATERIALS AND METHODS}

\section{Collection and identification of Stereum hirsutum}

The fruiting body of $S$. hirsutum was collected from Changgyeonggung, Seoul and brought in the Applied Microbiology Laboratory, Department of Biology, University of Incheon, Korea. To identify the species, we studied morphological characteristics, isolated, cultured on potato dextrose agar (PDA) medium and incubated at $25{ }^{\circ} \mathrm{C}$ for further study. For molecular identification, a polymerase chain reaction (PCR) was done using universal primers ITS1 (5'-TCCGTAGGTGAACCTGCG-3') and ITS4 (5'-TCCTCCGCTTATTGATATGC-3'). The mycelial pure culture was deposited to Culture Collection and DNA Bank of Mushrooms (CCDBM), Korea and acquired accession number of University of Incheon Mushroom (IUM). The sample used in this experiment was performed with 5 replications. 


\section{DNA isolation}

Mycelia of $S$. hirsutum was grown on PDA, harvested using a spatula, transferred into $1.5 \mathrm{ml}$ eppendorf tube, freeze-dried (Operon, Korea) and ground into powder with a pestle using liquid nitrogen. As extraction buffer, equal amount of $50 \mathrm{mM}$ Tris-HCl (pH 7.5), $50 \mathrm{mM}$ EDTA (pH 8) and 1\% sarkosyl was added to eppendorf tube, vortex (Barnstead Int., Model No. M37610-33, U.S.A.) and incubated at $65^{\circ} \mathrm{C}$ for $30 \mathrm{~min}$ in a steam water bath. After incubation, same amount of PCI (25 ml Phenol: $24 \mathrm{ml}$ Chloroform: $1 \mathrm{ml}$ Isoamylalcohol) was added, vortex and centrifuged at $4{ }^{\circ} \mathrm{C}$, $10 \mathrm{~min}, 12000 \mathrm{rpm}$. After that, only supernatant was taken into $1.5 \mathrm{ml}$ of Eppendorf tube, added $1000 \mu \mathrm{l}$ of 99.9\% ethyl alcohol and centrifuged at $4{ }^{\circ} \mathrm{C}, 5 \mathrm{~min}$, $12000 \mathrm{rpm}$. In this case, supernatant was removed, added $500 \mu \mathrm{l}$ of $70 \%$ alcohol to precipitated DNA, and again centrifuged at $4{ }^{\circ} \mathrm{C}, 5 \mathrm{~min}, 12000 \mathrm{rpm}$. Finally, supernatant was removed and waited until residual alcohol evaporated. In this stage, $500 \mu \mathrm{l}$ of sterilized distilled water was added and vortex 1 2 min (It's called stock solution). To check the DNA concentration using spectrophotometer (2120UV, OPTIZEN, Korea), $20 \mu$ l of DNA stock solution was added to $780 \mu \mathrm{l}$ of SDDW (Sterilized Double Distilled Water) and then $800 \mu \mathrm{l}$ of DNA mixture was taken in to covet and concentration was measured at 260 and $280 \mathrm{~nm}$. For control, concentration of SDDW of $800 \mu \mathrm{l}$ was measured. Finally, exact concentration of DNA solution was calculated.

\section{Polymerase chain reaction (PCR)}

The DNA of all samples was amplified (ITS1-5.8S rDNA-ITS2) by PCR (PTC-100TM, MJ Research Inc., U.S.A.) using universal primers ITS1 forward (5'-TCCGTAGGTGAACCTGCG-3') and ITS4 reverse (5'-TCCTCCGCTTATTGATATGC-3'). Amplification reactions were performed in a total volume of $20 \mu \mathrm{l}$ containing $10 \times$ PCR buffer $2 \mu \mathrm{l}$, dNTP $1.6 \mu \mathrm{l}, 0.5 \mu \mathrm{l}$ of each primer, $0.2 \mu \mathrm{l}$ of Taq polymerase (Cosmo, Korea), $1 \mu \mathrm{l}$ of genomic DNA and $14.2 \mu \mathrm{l}$ of sterilized distilled water. PCR amplification was carried out 30 cycles at $94^{\circ} \mathrm{C}$ for $30 \mathrm{sec}$ denaturing, $51^{\circ} \mathrm{C}$ for $30 \mathrm{sec}$ annealing and $72^{\circ} \mathrm{C}$ for $1 \mathrm{~min}$ extension. Initial denaturing at $95^{\circ} \mathrm{C}$ was extended to $5 \mathrm{~min}$ and the final extension was at $72^{\circ} \mathrm{C}$ for $10 \mathrm{~min}$ (Fig. 1).

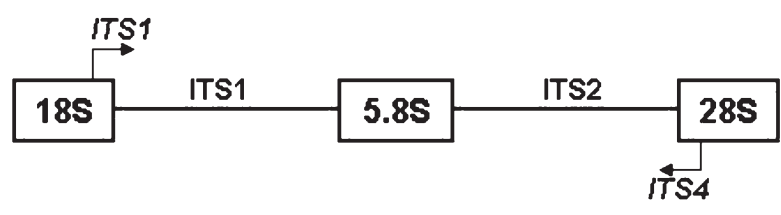

Fig. 1. Schematic representation of ribosomal DNA repeats unit and the location of the primers on the ITS region.

\section{Gel electrophoresis and sequencing}

Amplified PCR products were separated by gel electrophoresis containing $1.5 \%(\mathrm{w} / \mathrm{v})$ agarose (Blue marine
200, Serva Electrophoresis). The electrophoresis was run in $1 \times$ TAE buffer and the amplified products were visualized by ethidium bromide staining under UV light. The length of amplified products was estimated by comparing to DNA size marker. After confirmation of certain PCR amplification, PCR product was sent to sequencing company (SolGent Co. Ltd, Korea) and sequence was obtained.

\section{Analysis of DNA sequences}

To make DNA sequences, two universal primers (ITS1 \& ITS4) were used. Analysis of sequences was performed with the basic sequence alignment BLAST (Basic Local Alignment Search Tool) program run against the NCBI (National Centre for Biotechnology Information) database. Sequence alignment was done using CLC sequence viewer software.

\section{Use of microorganisms}

Three Gram-negative bacteria (Escherichia coli CCARM1258, Klebsiella pneumoniae CCARM10161 and Pseudomonas aeruginosa CCARM2171) and two Gram-positive bacteria (Bacillus subtilis IUB3251 and Staphylococcus aureus CCARM3230) were used in this study. B. subtilis was collected from Applied Microbiology Laboratory, Department of Biology, University of Incheon and remaining 4 bacteria were obtained from Culture Collection of Antibiotic Resistant Microbes (CCARM), Korea. The bacterial strains were maintained on nutrient agar (NA) at $4{ }^{\circ} \mathrm{C}$.

\section{Collection of crude extract}

The fungus $S$. hirsutum was cultured both in liquid nutrient medium (LNM) and PDA medium separately. The LNM culture was incubated at $25^{\circ} \mathrm{C}$, on rotary shaker 140 150 rpm and PDA culture was incubated at $25^{\circ} \mathrm{C}$ for 30 days. After incubation, solid culture was dried in fume hood (HK-FH1800, Korea), powdered and then extracted both in distilled water and $70 \%$ ethyl alcohol ( $1 \mathrm{~g}: 15 \mathrm{ml})$ separately for 72 hours at $25^{\circ} \mathrm{C}$. To achieve filtrates, the LNM, water extract and ethanol extract were filtered through 2 layers of Whatman No. 1 filter paper. The 3 different filtrates were concentrated by a rotary evaporator (Eyela, Tokyo Rikakikai Co. Ltd., Japan) until semi-solid state substances were obtained. The semi-solid state substances were then freezing dried at $-80^{\circ} \mathrm{C}$ (Operon, Korea). After that, the samples were uses for further experiments.

\section{Assay for antibacterial activity}

Optical density (OD) method: The antibacterial activity of liquid culture filtrate was evaluated in LNM measuring optical density (OD) using spectrophotometer (2120UV, OPTIZEN, Korea). Cultures of LNM was filtered through Whatman No. 1 filter paper and incorporated with fresh LNM at 50\% concentration (v/v) and autoclaved at $121{ }^{\circ} \mathrm{C}$ for 15 minutes. Cooled liquid medium was aseptically inoculated with each bacterium separately in $250 \mathrm{ml}$ conical flask and incubated at $37^{\circ} \mathrm{C}$. The bacterial growth was determined by counting OD 
value at $600 \mathrm{~nm}$ every 6 hours and it was done until 36 hours. For control, fresh LNM was also inoculated by each bacterium and OD value was measured with same method.

Paper disc method: A modified filter paper disc method (Norrel, 1997) was also used to determine the antibacterial activity. The samples (crudes of liquid culture, water extract and ethanol extract) were diluted to $10 \%$ solution $(0.1 \mathrm{~g} / \mathrm{ml})$ with sterilized distilled water for experiment. The sterile paper discs $(8 \mathrm{~mm}$ diameter, Toyo Roshi Kaisha Ltd., Japan) were soaked with $50 \mu \mathrm{l}$ of the aliquot and placed on a bacterial seeded plate $\left(10^{5}\right.$ $\mathrm{CFU} / \mathrm{ml}$ ) of nutrient agar. The plates were incubated at $37^{\circ} \mathrm{C}$ for 24 hours and the inhibition zone was observed and calculated. An average inhibition zone was considered for 5 replicates.

\section{RESULTS AND DISCUSSION}

\section{Confirmation of species}

PCR analysis is one of the most advanced techniques to confirm the biological species. The sequence of PCR product was compared to NCBI database (National
Centre for Biotechnology Information/http://www.ncbi. nlm.nih.gov/BLAST). According to the taxonomic report of BLAST, result indicates that the studied fungus was $S$. hirsutum species which similar to NCBI database (Maximum and total score 1048, Query coverage 100\%, E value 0.0 and Maximum identity $99 \%$ compare to consensus reference strain dd08031, Accessio No. gil226346602| FJ810148.1). The following sequences (Length: $558 \mathrm{bp}$ and Weight: $179.45 \mathrm{kDa}$ ) were found after PCR experiment of the studied sample. BLAST computes a pairwise alignment between the query and database sequences searched. In neighbor joining tree, sequence of studied sample was placed with consensus other similar sequences of database mentioning the taxonomic name and sequence title that indicate the studied sample was suppose to be $S$. hirsutum species (Table 1 and Fig. 2).

<TATGACTGGGGTTGTCGCTGGCCTATAAAACGGCATGTGCACGCTCCTTTCACAATCCACACACACCTGTGCACCTTCGCGGGGGTCTTCTCTCTTCGGAGAGGAGGCTCGCGTCCCTTTACACACCCTTTGTATGTCTTAAGAATGTCTACTCGATGTAATAAAACGCATCTAATA-

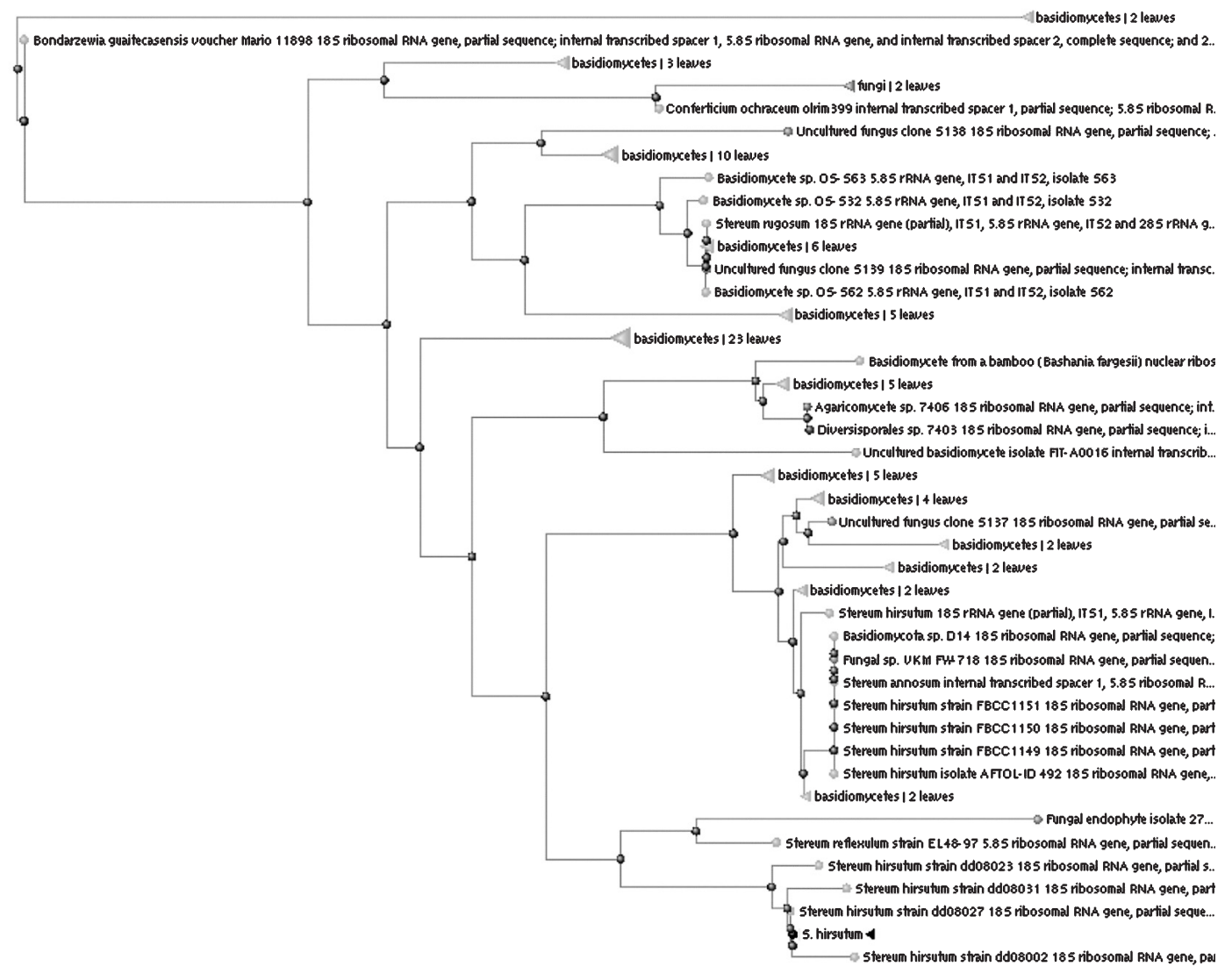

Fig. 2. The neighbor joining tree was produced using BLAST pairwise alignments. BLAST computes a pairwise alignment between a query and the database sequences searched. It does not clearly calculate an alignment between the different database sequences (i.e., does not perform a multiple alignment). For purposes of this sequence tree presentation an implicit alignment between the database sequences is constructed, based upon the alignment of those (database) sequences to the query. It may often occur that two database sequences align to different parts of the query, so that they hardly overlap each other or do not overlap at all. In that case it is not possible to calculate a distance between these two sequences and only the higher scoring sequence is included in the tree. 
Table 1. Statistics of nucleotide sequences of ITS region

\begin{tabular}{lcc}
\hline Base (s) & Count & Frequency \\
\hline Adenine (A) & 125 & 0.224 \\
Cytosine (C) & 142 & 0.254 \\
Guanine (G) & 132 & 0.237 \\
Thymine (T) & 159 & 0.285 \\
C + G & 274 & 0.491 \\
A + T & 284 & 0.509 \\
\hline
\end{tabular}

Frequency was calculated as $\mathrm{P} /(\mathrm{A}+\mathrm{T}+\mathrm{C}+\mathrm{G})$ where $\mathrm{P}=$ Any of $\mathrm{A}, \mathrm{T}, \mathrm{C}, \mathrm{G},(\mathrm{C}+\mathrm{G})$ and $(\mathrm{A}+\mathrm{T})$.

CAACTTTCAACAACGGATCTCTTGGCTCTCGCATCGATGAAGAACGCAGCGAAATGCGATAAGTAATGTGAATTGCAGAATTCAGTGAATCATCGAATCTTTGAACGCACCTTGCGCCCTTTGGTATTCCGAAGGGCACACCTGTTTGAGTGTCGTGAAATTCTCAACCCTCTTCGCTTTTTTGCGAACGTAGGGATTGGACTTGGAGGCTTTGCCGGGCTTCACATGCTCGGCTCCTCTCAAATGCATTAGT GCGTCT T GT T GCGACGT GCGCCTCGGTGTGATAATTATCTACGCTGTGGTGGGCTCGCTTCTGTAGAGACACGCTTTCTAACCGTCCGAAAGGACAGCTTTCATCGAACTTGACCTCAAATCAGGTGG>

Many evidences say that the ITS region can easily be amplified by PCR, using primers annealing in the conserved neighboring genes, and constitutes one of the most extensively applied molecular markers in phylogenetics and species differentiation. Mentionable that, the
5.8S gene shows a slow rate of evolutionary change, but the level of sequence dissimilarity of the spacers is higher (Hillis et al., 1991) and they can be used to conclude phylogenetic relationships from populations to families and even higher taxonomic levels (Coleman and Vacquier, 2002; Gonzá Lez, 1990; Vogler and Desalle, 1994). As members of a sequence family, the multiple copies of the ITS do not progress independently. They tend to change in a concerted fashion, which means that in a species the repeats evolve together, maintaining high similarities among themselves, as they diverge from repeats in other species (Arnheim, 1983; Dover, 1982). Unequal crossing-over and gene conversion are the prominent mechanisms responsible for the homogenization of sequences. Nevertheless, variation among repeats within genomes has been documented in a range of taxa (Gandolfi, 2001; Harris and Crandall, 2000; Hartmann, 2001; Mayol and Rossello, 2001; Xu, 2009) showing that the level of intraindividual variation should be considered to interpret accurately the information provided by the ITS region.

\section{Antibacterial assay}

The findings of optical density referred that the filtrate of $S$. hirsutum was found to inhibit both Gram positive and Gram negative bacteria. B. subtilis and $P$. aeruginosa are highly inhibited by the culture filtrate. The lowest inhibition was found for $K$. pneumoniae but after 24 hours of incubation inhibition rate was high. $E$. coli and $S$. aureus were inhibited moderately in the culture filtrate. In case of $E$. coli, growth rate was high both in treatment and control condition (Fig. 3). Ishikawa et al. (2001) reported that the mycelial culture filtrate of

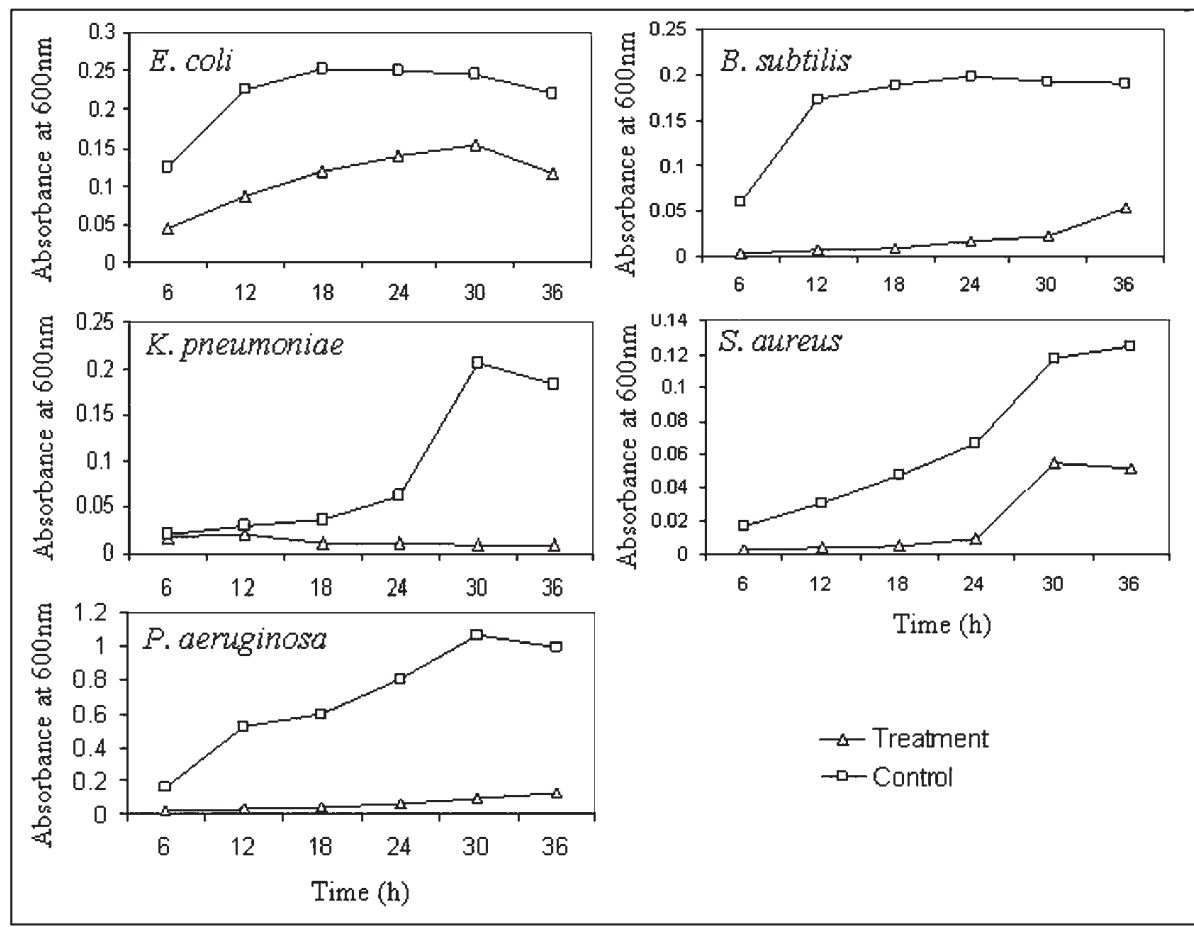

Fig. 3. Inhibition of bacterial growth measured $(n=5)$ in the mixture of $50 \%(v / v)$ liquid culture filtrate of $S$. hirsutum and fresh LNM. Absorbance value in liquid culture filtrate (treatment) smaller than control indicates inhibition. 


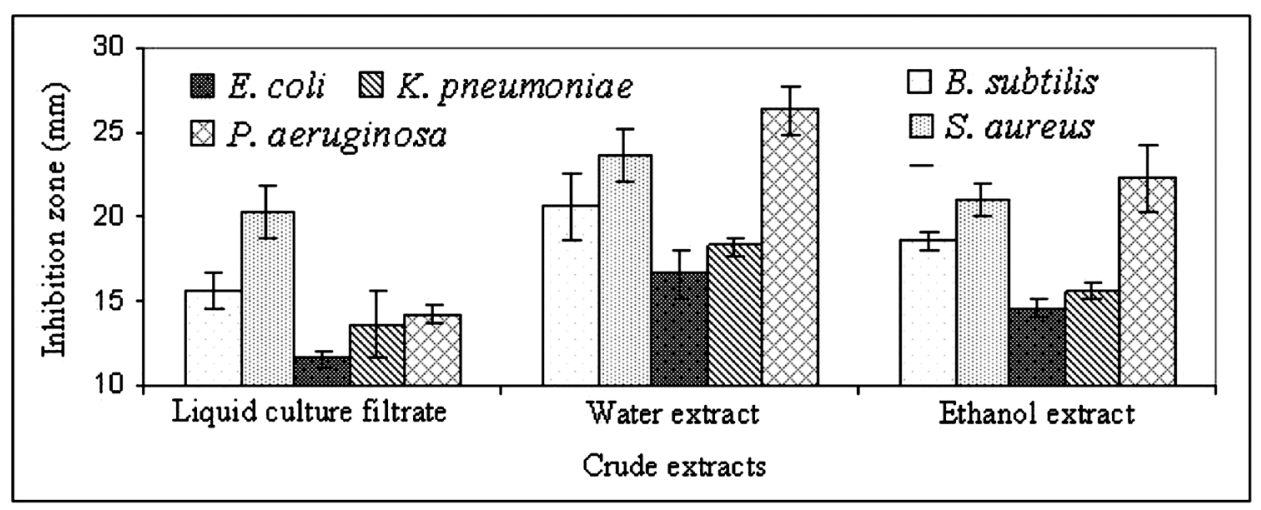

Fig. 4. Antibacterial effect of crude extracts measured on nutrient agar medium. Crude extracts were used at $50 \mathrm{mg} / \mathrm{ml}$ concentration. Each paper disc was soaked with $50 \mu \mathrm{l}$ of aliquot. Inhibition zone was measured $(n=5)$ after 24 hours of incubation at $37^{\circ} \mathrm{C}$.

Lentinula edodes was used against the growth of $B$. subtilis and got potential inhibitory effect. Imtiaj and Lee (2007) investigated an experiment on antibacterial activities of nine Korean wild mushrooms and found that, 20 days old liquid culture filtrates of $S$. ostrea, Pycnoporus cinnabarinus, P. coccineus, Oudemansiella mucida and Cordyceps sobolifera showed good antibacterial effects. Komemushi et al. (1995) also studied the inhibitory effect of $L$. edodes upon Gram-positive and Gramnegative bacteria was observed and the result of inhibition was found to be good for Gram-positive bacteria which are quite similar to this finding.

The results obtained from the paper disc method, all of 5 bacteria were less or more inhibited by the 3 types of culture filtrates (Fig. 4). Liquid culture and water extracts were demonstrated the lowest and highest inhibition zones of studied bacteria, respectively. In liquid culture, the highest and lowest inhibitions were found to be seen for $S$. aureus and $E$. coli, respectively. In case of water and ethanol extracts, $P$. aeruginosa, $S$. aureus and $B$. subtilis were highly inhibited, respectively as well as E. coli and K. pneumoniae were less inhibited in all extracts. Imtiaj et al. (2007) investigated an experiment on antibacterial activities of a Korean wild mushrooms $S$. ostrea and found culture filtrates showed good antibacterial effects on both Gram positive Gram negative bacteria. Two edible Nigerian macro-fungi Lycoperdon pusilum and L. giganteum were selectively active on few clinical pathogenic microorganisms (Jonathan, 2003). A paper disc method is used by Al-Fatimi (2006) and stated that the fungus Podaxis pistillaris was found to exhibit a strong antibacterial activity against several Gram-positive and Gram-negative bacteria such as $S$. aureus, Micrococcus flavus, B. subtilis, Proteus mirabilis, Serratia marcescens and E. coli.

\section{CONCLUSION}

In this study, we confirmed identification of a fungal species and its different culture filtrates have been used in vitro to observe the inhibitory effect against disease causing 5 bacteria. It can therefore be recommended that, it could be promising antimicrobial compounds and this work is already in ladder promote to identify bioactive compound. The achieved results may also be valuable to evaluate substances of interest formed by the fungus.

\section{REFERENCES}

Al-Fatimi, M. A. A., W. D. Julich, R. Jansen and U. Lindequist 2006 Bioactive components of the traditionally used mushroom Podaxis pistillaris. eCAM, 3: 87-92

Arnheim, N. 1983 Concerted evolution of multigene families. In: Evolution of genes and proteins (M. Nei \& R. K. Koehn eds), Sinauer Associates, Sunderland, MA. pp. 38-61

Coleman, A. W. and V. D. Vacquier 2002 Exploring the phylogenetic utility of ITS sequences for animals: a test case for abalone (Haliotis). J. Mol. Evol., 54: 246-257

Dover, G. 1982 Molecular drive: a cohesive mode of species evolution. Nature, 299: 111-117

Gandolfi, A., P. Bonilauri, V. Rossi and P. Menozzi 2001 Intraindividual and intraspecies variability of ITS 1 sequences in the ancient asexual Darwinula stevensoni (Crustacea: Ostracoda). Heredity, 87: 449-455

Gonzá Lez, I. L., J. E. Sylvester, T. F. Smith, D. Stambolian and R. D. Schmickel 1990 Ribosomal RNA gene sequences and hominoid phylogeny. Mol. Biol. Evol., 7: 203-219

Harris, D. J. and K. A. Crandall 2000 Intragenomic variation within ITS1 and ITS2 of freshwater crayfishes (Decapoda: Cambaridae): implications for phylogenetic and microsatellite studies. Mol. Biol. Evol., 17: 284-291

Hartmann, S., J. D. Nason and D. Bhattacharya 2001 Extensive ribosomal DNA genic variation in the columnar cactus Lophocereus. J. Mol. Evol., 53: 124-134

Hillis, D. M. and M. T. Dixon 1991 Ribosomal DNA: molecular evolution and phylogenetic inference. Quart. Rev. Biol., 66: $411-453$

Imtiaj, A. and T. S. Lee 2007 Screening of antibacterial and antifungal activities from Korean wild mushrooms. World J. Agri. Sci., 3: 316-32

Imtiaj, A., C. Jayasinghe, G. W. Lee and T. S. Lee 2007 Antibacterial and antifungal activities of Stereum ostrea, an inedible wild mushroom. Mycobiology, 35: 210-214

Ishikawa, N. K., M. C. M. Kasuya and M. C. D. Vanetti 2001 Antibacterial activity of Lentinula edodes grown in liquid medium. Brazilian J. Microb., 32: 206-210

Jonathan, S. G. and I. O. Fasidi 2003 Antimicrobial activities of two Nigerian edible macro-fungi Lycoperdon pusilum (Bat. Ex) and Lycoperdon giganteum (Pers.) African J. Biomed. Res., 6: 85-90

Komemushi, S., Y. Yamamoto and T. Fujita 1995 Antimicrobial substance by Lentinus edodes. J. Antibac. Antifung. 
Agents, 23: 81-86

Li, G. H., L. Li, M. Duan and K. Q. Zhang 2006 The chemical constituents of the fungus Stereum sp. Chem. Biod., 3: $210-216$

Mayol, M. and J. A. Rossello 2001 Why nuclear ribosomal DNA spacers (ITS) tell different stories in Quercus. Mol. Phylogen. Evol., 19: 167-176

Norrel, S. A. and K. E. Messley 1997 Microbiology laboratory manual principles and applications. Prentice Hall. Upper Saddle River, New Jersey

Vogler, A. P. and R. Desalle 1994 Evolution and phylogenetic information content of the ITS-1 region in the tiger beetle Cicindela dorsalis. Mol. Biol. Evol., 11: 393-405

Xu, J., Q. Zhang, X. Xu, Z. Wang and J. Qi 2009 Intragenomic variability and pseudogenes of ribosomal DNA in stone flounder Kareius bicoloratus. Mol. Phylogen. Evol., 52: 157-166 